\title{
THE ELECTROCARDIOGRAPHIC FEATURES OF HIGH POSTEROLATERAL MYOCARDIAL INFARCTION
}

\author{
BY \\ J. A. TULLOCH \\ From the Department of Cardiology, Royal Infirmary, Edinburgh \\ Received November 5, 1951
}

The cardiographic features of anterior and posterior myocardial infarction are well recognized. The occurrence of high lateral infarction has also been established, but infarction confined to the posterolateral aspect of the heart has in contrast received little attention. It is the purpose of this paper to stress the diagnostic cardiographic features of infarction in this area.

Anatomically the heart is an irregular and slightly flattened cone, with a base, an apex, and three surfaces, described anatomically as the sterno-costal, the diaphragmatic, and the left. Cardiographically, lesions of the sterno-costal and diaphragmatic surfaces are classified respectively as anterior and posterior. The left surface faces backwards, upwards, and to the left. It is not in close relationship to any of the six routine præcordial leads, but does in part face towards the left shoulder. Infarction confined to this left surface is posterolateral in position. As there is no lesion of the diaphragmatic surface, the infarct should be classed cardiographically as a " high" posterolateral infarct.

In 1944 Wilson pointed out that the combination of diagnostic changes of infarction in the left leg lead, unusual prominence of the $\mathrm{R}$ and $\mathrm{T}$ waves in leads to the right of the præcordium, and significant abnormalities in leads V5 and V6, was associated with infarction of the posterolateral aspect of the heart. Myers et al. (1949) have reported on 33 cases which at autopsy showed infarction of the posterolateral aspect, and have correlated the cardiographic and post-mortem findings. Changes in the left leg lead were taken as an index of the posterior aspect of the lesion, while the lateral extension was evidenced by præcordial leads V5 and V6 and the left arm lead. Less than one-third of the cases showed diagnostic changes in both limb leads. In the majority of cases changes of infarction were confined to one or other limb lead, depending on the exact size and position of the infarcted area, and on the position of the heart, particularly the degree of rotation around the long axis. Two cases showed no evidence of infarction in either limb lead. Sixteen cases were observed during the acute stage, and in eleven, præcordial leads from V1 to V4 showed reciprocal depression of the S-T segment, or exaggeration of the height of the $R$ and $T$ waves or of the $T$ waves alone, sufficient to arouse suspicion of posterolateral infarction. Both Wilson and Myers have illustrated their writings, but in no record does the $\mathrm{R}$ wave exceed the $\mathrm{S}$ wave in V1. Sears and Myers (1950) now record additional leads from the back of the chest in these cases, but have not as yet published their results. Recently Levy (1950) has stressed the occurrence of a prominent $R$ wave and shallow $S$ wave in lead V1 in lateral infarction; in eight of his twelve cases, the infarct was localized to the posterolateral aspect, but autopsy confirmation was apparently not available.

\section{MATERIAL}

Thirteen patients, four of whom have been followed to necropsy, provide the material for this paper. In all cases, the standard leads, unipolar limb leads, and præcordial leads V1 to V6 were recorded. Additional leads taken from points in the interspaces vertically above V4 to V6 were 
obtained in seven cases; while in six leads were also taken from the back of the chest. Leads V7, V8, and V9 were recorded from the left side of the chest, at the posterior axillary line (V7), subscapular line (V8), and paravertebral line (V9) respectively, at the same horizontal level as leads V4 to V6 (i.e. the horizontal level of the fifth left interspace at its junction with the mid-clavicular line). High leads on the back of the chest were taken from points vertically above V7 to V9, at the horizontal level of the third interspace at its junction with the sternum. In the normal healthy person, leads $V 7$ to $V 9$ show an upright $P$ wave, a small narrow $Q$ wave, a moderate $R$ wave, and an upright $\mathrm{T}$ wave. The higher leads taken above $\mathrm{V} 7$ to $\mathrm{V} 9$ are of similar form but are of lower voltage. Fig. 1 illustrates the tracings obtained from a healthy person in whom the heart was vertical in position. In posterior infarction, where the lesion is confined to the diaphragmatic surface, these additional leads are also of normal form.

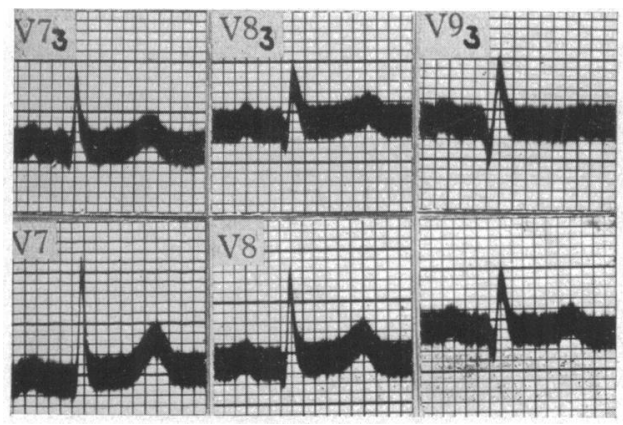

FIG. 1.-The records illustrate the normal form of complex in leads taken from points on the back of the chest in the left posterior axillary line, scapular line, and paravertebral line, (1) at the same horizontal level as the routine præcordial leads (V7, V8, and V9 respectively) and (2) at the horizontal level of the third interspace at its junction with the sternum (V73, V83, and V93 respectively). The heart was vertical in position.

The first patient, whose initial record is illustrated in Fig. 2, was originally diagnosed as having sustained a high lateral infarct, but the additional leads taken in the first, second, third, and fourth interspaces vertically above V4 to V6 were within normal limits. The presence of S-T depression in V4 and V5 in the original record, and the subsequent development of a tall $R$ wave in $V 1$ and high upright $T$ waves in the præcordial leads, suggested that the infarct was on the posterior surface, and was in fact posterolateral in position. At autopsy, three months after the acute attack, a large healed infarct, oval in shape, $5 \times 7 \mathrm{~cm}$. in size, and involving the full thickness of the left ventricular muscle, was demonstrated on the posterolateral aspect.

The record shown in Fig. 3 was obtained 5 days after a coronary thrombosis in a man, aged 52 years. The standard and unipolar limb leads show changes that, classically, are associated with infarction of the anterior surface of the heart, but the præcordial leads V1 to V6 show no certain evidence of anterior infarction. High leads taken from the interspaces above V4 to V6 also failed to demonstrate dead muscle. Inspection of the præcordial leads does reveal certain unusual features-the tall $R$ wave in $V 1$, the relatively deep $S$ wave in $V 6$, the absence of a definite transitional zone, the high upright $\mathrm{T}$ waves in $\mathrm{V} 2$ and V3, and the slight $\mathrm{S}-\mathrm{T}$ elevation with low upright $\mathrm{T}$ waves in V5 and V6. Serial records (Fig. 4) revealed changes typical of infarction in the left arm lead and in standard lead I; persistence of the predominance of $\mathrm{R}$ in V1, and the deep S wave in V6; reduction in the height of the T waves in V2 and V3; and development of $T$ wave changes suggestive of underlying muscle damage in V5 and V6. Leads taken from the back of the chest revealed the typical serial changes of recent underlying myocardial infarction (Fig. 5). In the record illustrated, leads V7 and V8 are overlying the edge of the infarct, but in the leads taken above V7 and V8, in the horizontal level of the 3rd interspace at its junction with the sternum, the initial deflections consist of a small broad $Q$ wave, and a small $R$ wave, with, in the first record, elevation of the S-T segment; and, in subsequent records, inversion of the $T$ wave of coronary type. The $P$ waves in these leads are upright, showing that the electrodes do in fact face ventricular muscle, and not the back of the heart.

Three other cases showed this general pattern in the twelve leads routinely recorded, and additional leads from the back of the chest revealed the infarcted area. Four further cases were different in that the initial deflections in the præcordial leads were within normal limits (Fig. 6). All showed abnormally high $\mathrm{T}$ waves in two or more of the præcordial leads, and in two cases 

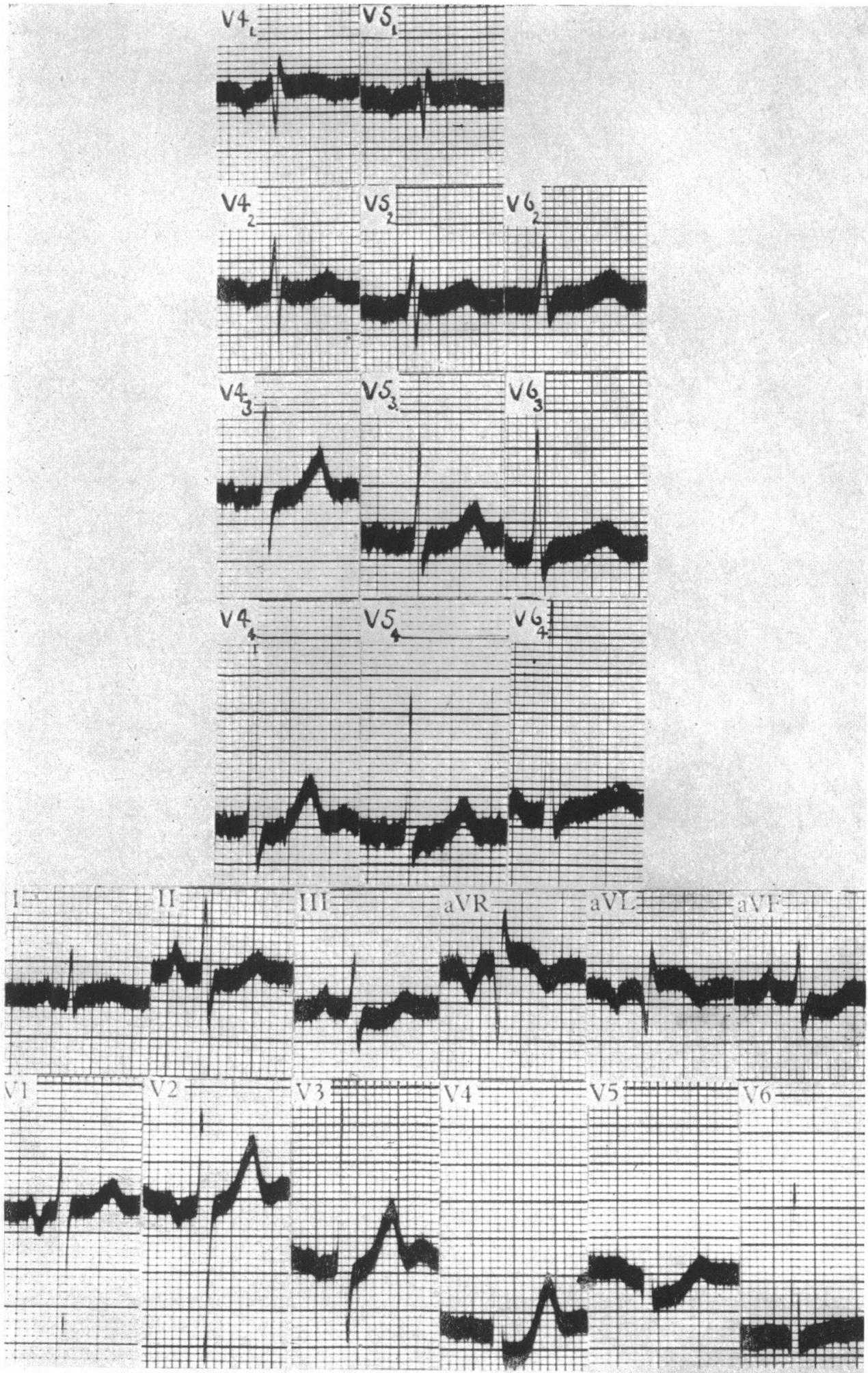

FIG. 2.-Cardiogram of Case 1 showing evidence of high lateral infarction in the unipolar limb leads. The additional leads taken fiom the first, second, third, and fourth interspaces vertically above V4, V5, and V6 fail to reveal underlying damaged muscle. 


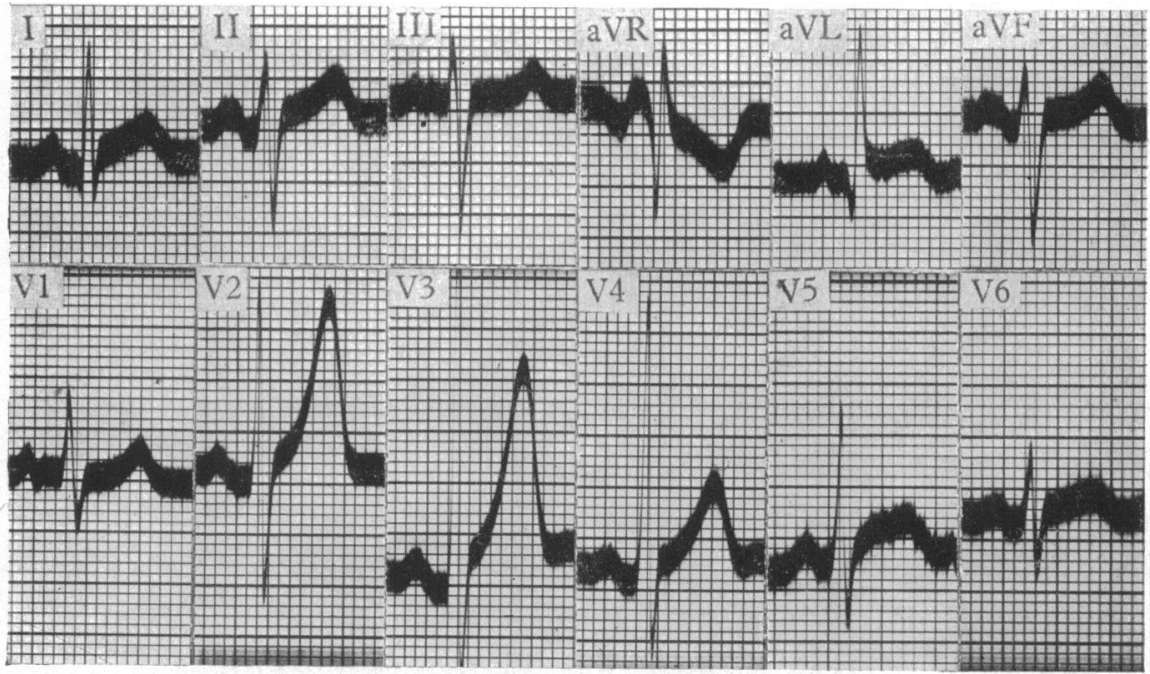

Fig. 3.-Cardiogram taken 5 days after a coronary thrombosis in Case 2.

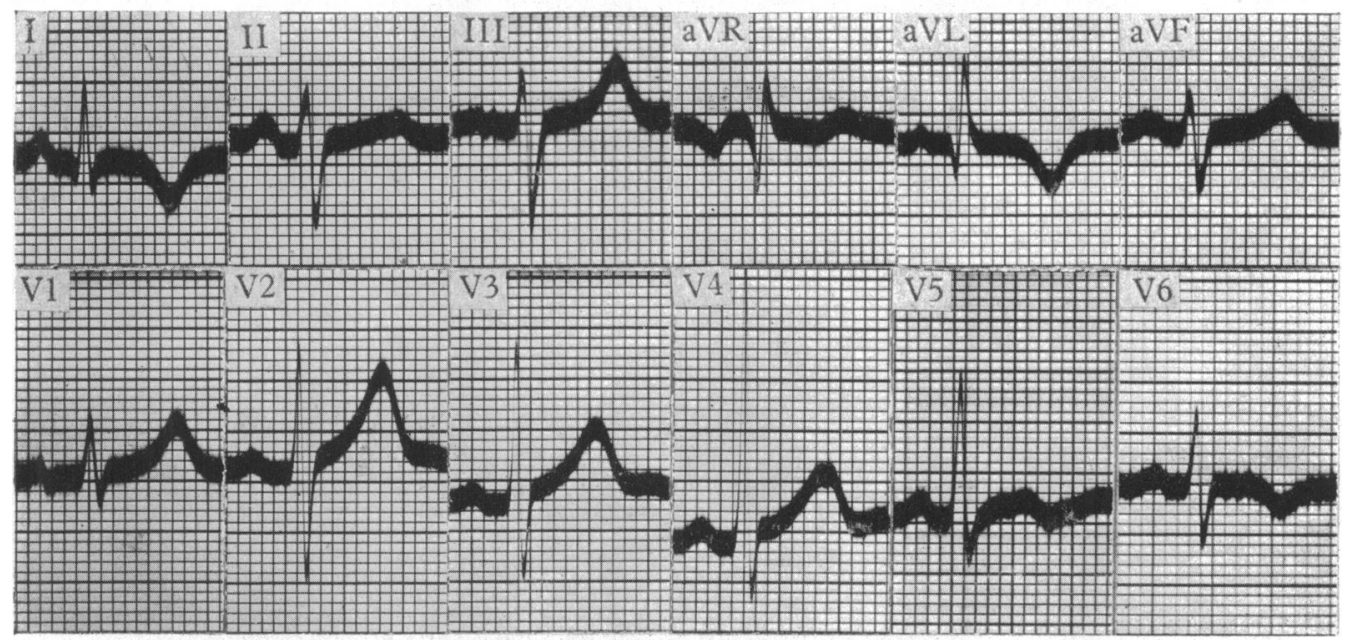

FIG. 4.-Cardiogram taken 27 days after the coronary thrombosis in Case 2.

there was also S-T depression in the acute stage. Changes suggestive of infarction were present in the left arm lead and in standard lead I.

The remaining four cases showed a slightly different pattern, but the changes, once recognized, were equally diagnostic. The record illustrated in Fig. 7A was obtained six weeks prior to the development of a coronary thrombosis in a male, aged 55 years, who had reported with symptoms of left ventricular failure and had well marked hypertension. It shows evidence of left ventricular hypertrophy. Fig. 7B was recorded five days after a clinical coronary thrombosis in this patient. There was no definite cardiographic evidence of myocardial infarction, but the reduction in the height of the $R$ wave in the left arm lead and in standard lead I, coupled with the S-T depression in V4 to V6 suggested the presence of diffuse subendocardial necrosis in the left ventricle. Necropsy after 19 days showed a transmural infarct on the posterolateral aspect of the left ventricle, extending in a strip just over one inch wide from near the auriculoventricular sulcus to just above the 


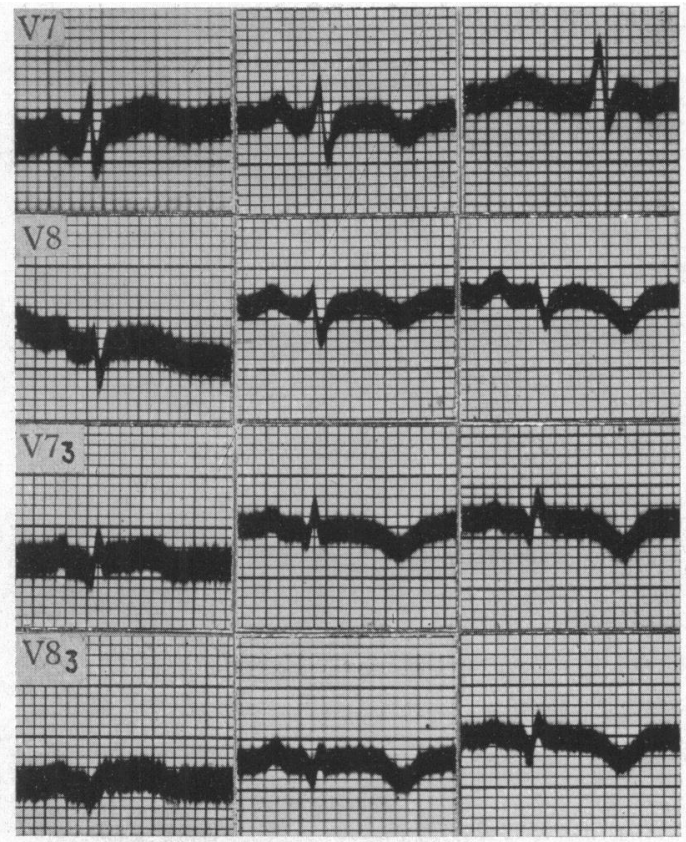

Fig. 5.-Records taken from the back of the chest in Case 2, at 5, 19 and 27 days after the coronary thrombosis. The electrodes were placed in the manner described in Fig. 1.

apex (Fig. 8). A considerable mass of hypertrophied left ventricle remained between the infarct and the posterior edge of the interventricular septum. Two other patients in whom the cardiogram showed essentially similar features have since been observed. In each the diagnosis was confirmed at necropsy, a strip of infarcted muscle being demonstrated on the posterolateral aspect of the left ventricle. The fourth case differed slightly in that there was no associated cardiographic evidence of left ventricular hypertrophy and was some S-T depression in the præcordial leads, mainly

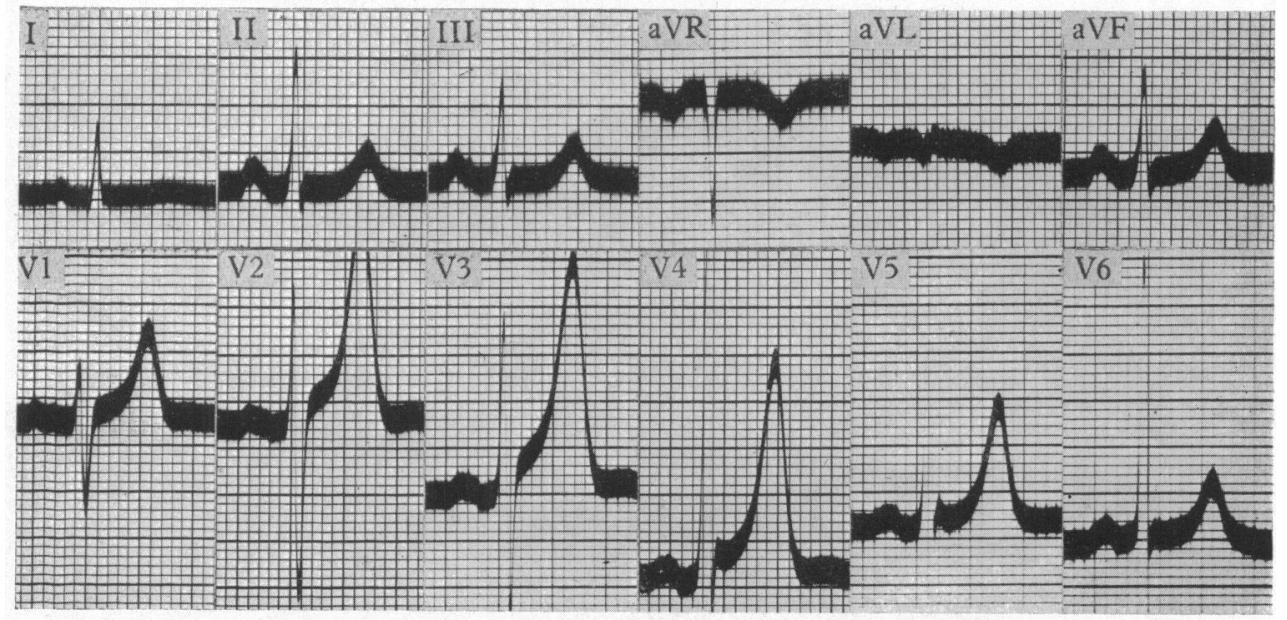

FIG. 6.-Cardiogram showing abnormal high $\mathrm{T}$ waves in the præcordial leads, with no QRS changes. 
in V1 to V4. Serial leads taken from the back of the chest in this patient (from the points previously described), showed $\mathrm{S}-\mathrm{T}$ and $\mathrm{T}$ wave changes diagnostic of underlying infarction.

\section{Discussion}

The left shoulder faces both the sterno-costal and left surfaces of the heart. Infarction high on either surface and lateral in position may therefore be detected in the left arm lead. Should additional leads taken from the intercostal spaces above V4 to V6 prove normal in such a case, then leads taken above V7 and V8 will reveal underlying muscle damage. It is suggested that the following five features occurring in the twelve leads routinely recorded ( 3 standard limb leads, 6 unipolar præcordial leads, and 3 unipolar limb leads) constitute one pattern of high posterolateral myocardial infarction-(1) evidence of infarction in the left arm lead, and so in standard lead I;

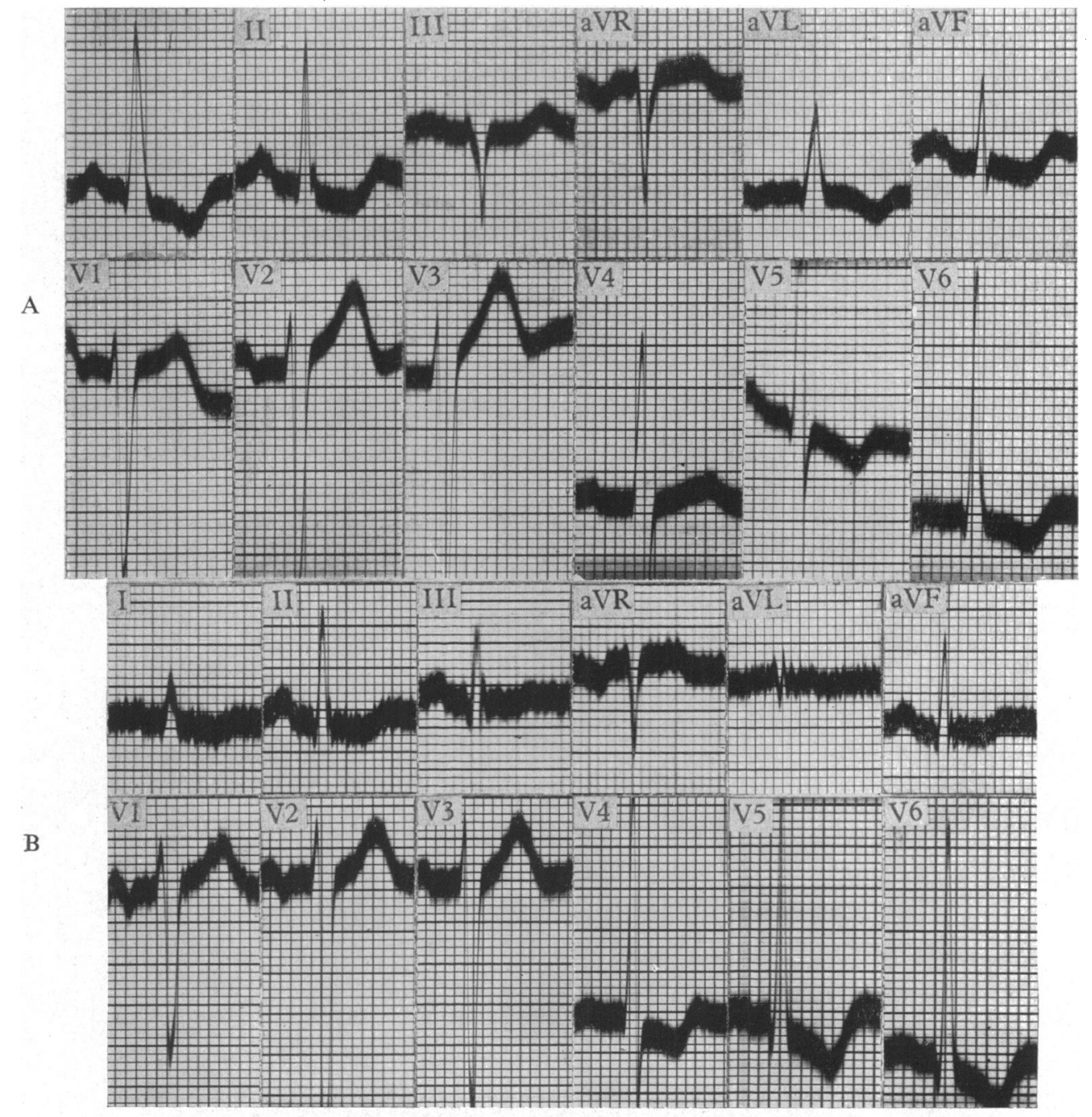

FIG. 7.-(A) Cardiogram of Case 10 recorded six weeks before the myocardial infarct showing evidence of left ventricular hypertrophy; (B) Cardiogram obtained 5 days after a clinical coronary thrombosis in this patient. 
(2) a predominant $\mathrm{R}$ wave in V1; (3) absence of a definite transitional zone in the præcordial leads; (4) high $\mathrm{T}$ waves in two or more of the præcordial leads; and (5) in the acute stage, S-T depression in the præcordial leads. The depth of the $\mathrm{S}$ wave in V6 may be helpful, but in some cases this $\mathrm{S}$ wave is not abnormal. Chest leads V5 and V6 commonly overlie the edge of the infarcted area.

The tall R wave in V1 and the deep S wave in V6 (Fig. 3 and 4) are probably due to relative predominance of the right ventricle. This could occur in a previously normal heart were the left ventricular muscle on the back of the heart damaged. Serial records taken from the back of the chest in the horizontal levels of the fifth and third interspaces anteriorly should overlie and demonstrate the infarcted area, and in fact do so (Fig. 5).

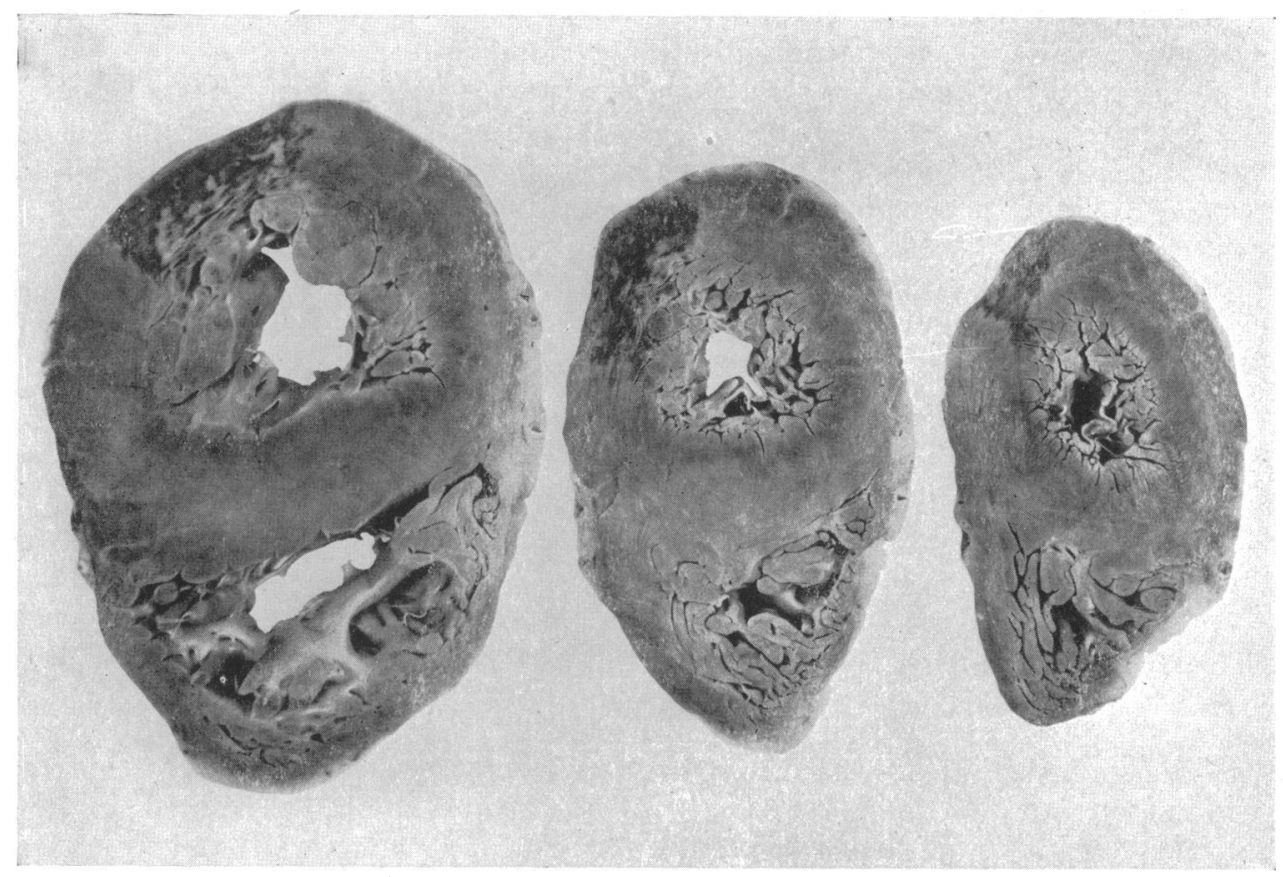

FiG. 8.-Serial sections of the heart in Case 10 showing the left ventricular hypertrophy and the strip of infarcted muscle on the posterolateral aspect.

As might be expected, the exact size and position of the infarcted area, the position of the heart and the form of the cardiogram prior to the development of the infarct, are important in determining the changes resulting from infarction. As stated, five of the cases showed the pattern just described. In these, the heart was horizontal or intermediate in position. Forward rotation of the apex may, without changing the præcordial lead pattern, alter the form of the leads from the left arm and the left leg, bringing the diagnostic changes of infarction into the left leg lead. This occurred temporarily in one case. In no other case did the left leg lead show diagnostic changes of infarction, indicating that the diaphragmatic surface of the heart was intact. In each of the four cases showing no abnormality of the initial deflections in the præcordial leads the heart was electrically vertical or intermediate in position. The normal form of the initial deflections in the præcordial leads may indicate that the area of infarction is small, and that there is an adequate mass of left ventricular muscle opposing the right ventricle. This contention is supported by the findings at necropsy in the three cases showing cardiographic evidence of left ventricular hypertrophy, one of which is illustrated in Fig. 7 and 8 . In these cases the left ventricle was grossly hypertrophied, and the area of infarction was long and narrow with a mass of hypertrophied muscle behind it. After the 
development of the infarct, the cardiographic evidence of left ventricular hypertrophy therefore tends to persist in præcordial leads V1 to V6, and to distort and obscure the changes produced by muscle damage and death on the posterolateral aspect. In such cases the features suggestive of high posterolateral infarction are (1) the presence in the præcordial leads V1 to V6 of normal initial deflections, or of increase in the depth of the $S$ wave in V1 and V2 and in the height of the R wave in V5 and V6, due to the left ventricular hypertrophy; (2) S-T depression in the præcordial leads, which, if there are S-T and T wave changes of left ventricular hypertrophy, occurs in leads further to the right than would be expected if left ventricular hypertrophy alone were present; (3) presence of a small and sometimes bifid $\mathrm{R}$ wave in the left arm lead and standard lead I, out of keeping with the height of the $\mathrm{R}$ waves in V5 and V6, and associated with a flat or inverted T wave. The T waves in V2 and V3 may not be abnormally tall. In the absence of left ventricular hypertrophy inversion of the T wave of " coronary type" may develop in V5 and V6.

Not only may the evidence of posterolateral infarction be suppressed by the presence of left ventricular hypertrophy, but it is possible that, some days or weeks after the infarct has been sustained, the pattern of infarction in the left arm lead may be mistaken for that of left ventricular hypertrophy. Attention to the breadth of the $Q$ wave, the relative height of the $R$ wave, and the symmetrical inversion of the T wave, should minimize such difficulties (Goldberger, 1949).

\section{CONCLUSIONS}

Infarction of the anatomical left surface of the heart-high posterolateral infarctionproduces characteristic changes in the twelve cardiographic leads routinely recorded, when the infarct is of sufficient size. These changes are: (1) diagnostic signs of infarction in the left arm lead, and in standard lead I; (2) a predominant $\mathrm{R}$ wave in $\mathrm{V1}$; (3) absence of a definite transitional zone in the præcordial leads; (4) high upright $\mathrm{T}$ waves in two or more of the præcordial leads; and (5) in the acute stage, S-T depression in the præcordial leads. Leads V5 and V6 commonly overlie the edge of the infarct. Additional leads taken from the back of the chest demonstrate the infarcted area. The position of the heart, the size of the infarct, and the preceding cardiographic pattern, are all important in determining whether the full picture described above appears in the præcordial leads, or whether only S-T and T wave changes develop. In the presence of much left ventricular hypertrophy the following changes are associated with the occurrence of a high posterolateral infarct-(1) S-T depression in the præcordial leads, further to the right than found with left ventricular hypertrophy alone, and (2) reduction in the height of the $R$ wave in the left arm lead and standard lead I, out of keeping with the height of R in V5 and V6, and possible splintering of this small $R$ wave. The $T$ waves in the left arm lead and standard lead $I$ remain inverted, or become inverted, while in præcordial leads V2 and V3, abnormal high $\mathrm{T}$ waves may not develop.

\section{REFERENCES}

Goldberger, E. (1949). Unipolar Lead Electrocardiography. London.

Levy, L., Jnr., Jacobs, H. J., Chasant, H. P., and Strauss, H. B. (1950). Amer. Heart J., 40, 447.

Myers, G. B., Klein, H. A., and Hiratzka, T. (1949). Amer. Heart J., 38, 837.

Sears, C. H., and Myers, G. B. (1950). Amer. J. Med., 8, 808.

Wilson, F. N. et al. (1944). Amer. Heart J., 27, 19. 